\section{Restorative materials}

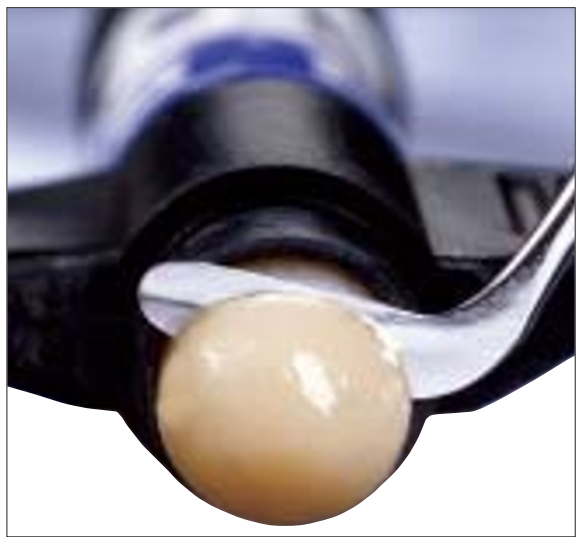

Visitors to Trycare Ltd's Stand L01 will be able see the aesthetic and handling properties of the complete range of patented Polycarbonate Pentron restorative materials, from which products like Build-It, Flow-it and Cement-It are made.

Other products which include the Rocky Mountain Allogenic Cancellous Bone, the Lifecore and Tatum Unipost Implant Systems, Molnlyke and a range of German Surgical Instruments are also on display. For further information visit Stand L01 or telephone Trycare Ltd on 01274881044 Reader response number 56

\section{Promoting oral health}

The Curaprox product range on stand J11 has solutions to promote improved oral health for every patient, according to its manufacturer.

Curaprox helps to prevent gingivitis and bad breath by compensating for the main weakness of tooth brushing with interdental plaque control.

The company claims that the product can make surfaces feel smoother, teeth appear whiter and gums feel firmer. Reader response number 57

\section{GSK portfolio}

GSK's personnel will be on hand on stand N10 to help and inform all visitors.

GSK's portfolio includes Corsodyl, Sensodyne, Poli-Grip, Macleans and Aquafresh.

There will also be new products on display from Sensodyne, Poli-Grip and Aquafresh.

Reader response number 58

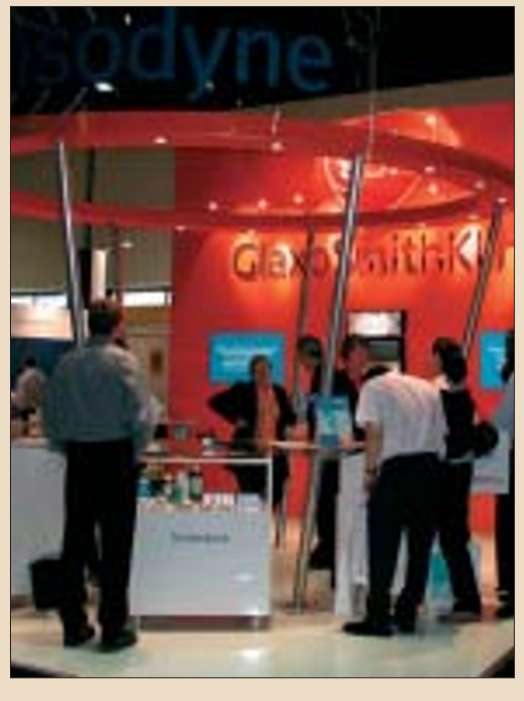

